\title{
Video Games and Agency in Contemporary Society
}

\section{Daniel Muriel \& Garry Crawford}

\begin{abstract}
In recent years, the idea of player control, or agency, has become central and explicit in certain video games and genres, affecting many debates concerning the study or definitions of video games. In spite of this, the notion of agency in video games has been rarely explicitly explored or defined in relation to its sociological and political dimensions. Hence, drawing on actor-network theory, (neo-)Foucauldian governmentality studies, and empirical data gathered over a three-year period, this paper expands to our understanding of video game player agency and moreover, argues that video games provide an important example and perspective to consider the contemporary nature and political basis of agency.
\end{abstract}

\section{Keywords}

Agency, Actor-Network Theory, Assemblage, Neoliberalism, Freedom, Video Games

\section{Introduction}

Interactivity is a noun often associated with video games. In fact, the interactive nature of video gaming is one of the main arguments regularly used to differentiate video games from other cultural products or media. It is frequently argued that in video games, players 'do not merely consume a pre-established piece of media, but instead are active participants in the creation of their experience' (Calleja, 2011: 56). This is then commonly offered as definitive evidence, by which, video games should be considered as the purest form of a new paradigm of cultural consumption (Kirby, 2009: 167); one that requires the explicit participation of the player. This is often then opposed to a more 
vertical model, traditionally tied to 'older' media such as television, cinema, or literature; delineating a movement from social models mainly attached to ‘spectatorship' (Debord, 1995) to those focused on 'participation' (Jenkins, 2006).

To be clear, it is obvious that players do not freely manipulate video games at their will; they are limited by the game's own restrictions and possibilities (Crawford, 2012). Similarly, especially in a context traversed by a widespread digital culture, those 'older media' are far from being passively consumed. And yet, we would wish to argue, video games do still occupy a privileged position from which to consider the contemporary nature of agency.

Video games have often been celebrated for being a medium that offers choices for those who play them, but we would suggest that in recent years this attribute has become even more central and explicit in certain games and genres; and there are several titles that explicitly explore the idea of player agency. For example, Until Dawn (Supermassive Games, 2015) and Life is Strange (Dontnod Entertainment, 2015) use the 'butterfly effect' metaphor and imagery to convey to the player that, everything they do, may affect the storyline and the characters' fate. In a similar vein, Dreamfall Chapters (Red Thread Games, 2014) warns players whenever a relevant choice has been made, by announcing that 'the balance has shifted'. Similarly, the recent oeuvre of TellTale Games such as The Walking Dead (2012-to date), The Wolf Among Us (2013), Game of Thrones (2014), Tales from the Borderlands (2014), and Batman: The TellTale Series (2016) let the player know that the story will be tailored by their choices. Other titles like Quantic Dream's Heavy Rain (2010), Beyond: Two Souls (2013) and Detroit: Become Human (2018) play with the same ideas and, in their case, offer multiple endings depending on the decisions made. Moreover, most often this type of game offers statistics at the end of each chapter - as these are presented in an episodic fashion 
- on the decisions made, allowing each player to compare their own choices with the rest of the population that have played the video game. The question of agency and the player's capacity to make significant changes are then at the centre of this trend in video games.

The idea of player control, or agency, is therefore central to many debates concerning the study or definitions of video games. However, in this context, the meaning and nature of agency is often taken as a given, and seldom has it been explicitly explored and defined in any real depth. This paper then seeks to identify the key aspects of player agency in video games, and in doing so, also provides an important lens for considering the contemporary nature of agency in a context dominated by social assemblages and neoliberal political rationalities. In particular, drawing on new and original empirical data gathered over a three-year period, this paper utilises video games as a lens for considering the nature and forms of agency in late modernity. Here, we suggest that the medium of video games exposes different forms and examples of agency, which allows us the opportunity to examine this important notion and its meaning within video game practices and wider culture.

This article is divided in two main sections. First, building mainly on actornetwork theory and the work of Michel Foucault, the paper begins by considering the notion of agency as the multiple, distributed, and dislocated production of differences and transformations that can take a multitude of forms. This then helps us to extend the definition of agency beyond its traditional limited scope of the human being, and also consider how video games, and the apparatuses in which they are produced, operate as agents as well as facilitators of action. As Bruno Latour (2017: 49n) argues 'even though the word "agency" in English often refers to persons...I take it, following the 
insights of semiotics, as a concept that precedes the attributions of humanity and personhood'. In this sense, from an ontological point of view, agency is defined as what transforms reality one way or another, and, politically, as what mainly operates within the framework outlined by the political rationalities linked to neoliberalism.

Second, we then explore the rhetorical and practical tendencies that surround agency in video game culture. In particular, the ideas of 'freedom', 'responsibility', and 'control' appear as indicators and expression of this agency. Video games present themselves as full of opportunities and choices to be made (even if these seem, in principle, to be very limited), and the responsibility to act is always bestowed on the player: which path to take, who should survive, what decision to make? Freedom is understood here in the terms of a (neo-)Foucauldian approach, and as part of contemporary neoliberal political rationalities. The hegemonic discourse in video game culture, therefore, prioritises the idea of the player as being in control; in control of their actions and the outcomes of these actions in the game. This makes the player responsible for both their achievements and failures, even though there are many other actors (not necessarily human) involved in the process. In the end, although the notion of agency in video games seems to be dominated by the referents of neoliberalism, it is still possible to glimpse ways in which agency can break through this 'wrapping' (Jameson, 1991) and head towards more promising outcomes.

Thus, this paper draws on data gathered from a larger research project on video game culture. Not only does the project aim to consider what sociology can tell us about the video game as experience, culture, or as a sociotechnical fabric, but it also seeks to comprehend how video games and their culture can help us understand wider social topics such as agency, power, everyday life, and identity in contemporary society. It is about approaching social issues of major importance through video games as a social 
reality that reflects (and promotes) those processes. Here, in this paper, we are specifically exploring the findings that revolve around the question of agency.

\section{Methods}

The primary method used within the research has been semi-structured interviews with twenty-eight participants in Germany, Sweden, Luxembourg, and the United States, but primarily, in the UK and Spain — some face-to-face, but most commonly via Skype. Despite focusing on just one area in this paper (the question of agency), we draw on all of our dataset, and in particular, cite nineteen out of twenty-eight interviewees. The interviewees were categorised, by the researchers, to broadly include individuals from a range of video game-related roles or groups. This includes, (but is not limited to) video gamers, developers (such as designers, programmers and artists), academics, journalists, website contributors and bloggers, and those in the arts and culture sector. It is important to note that these categories are only for sampling purposes, and were simply used to gather a broad range of actors implicated within video game culture. These categories are not necessarily mutually exclusive or even clearly bounded. However, significantly, where most empirical studies of video game culture focus on only a particular type or role of actor, such as video game players, developers, or journalist, this research explores the nature of this culture and its networks from multiple perspectives. The aim of this varied pool of participants is to grasp, on a small scale, using qualitative data, the diversity of actors that are part of video game culture. Our purpose is not to establish differences between video game industry professionals and video gamers, or between individuals from different nationalities or backgrounds (which are taken into account, nonetheless), but to study video game culture as a whole and its impact on society. All participants cited in the research have been given pseudonyms. 
In regards to 'video gamers', the interviewees were purposefully sampled according to their (self-defined) various levels of involvement within video game culture and their own definition as (or not) a 'gamer'. For example, some of them were highly involved in aspects of video game culture and self-identified as gamers, while others were less active and did not necessarily label themselves as gamers. The interviewees with members of the video game industry were chosen again to provide a range of participants according to their role within the industry (such as, managers, programmers, designers, artists, and marketing), type of company (size, if they are developers and/or publishers), and the kind of video games they worked with (AAA, indie, free-to-play games). The interviewees categorized as belonging to 'the media' were again purposefully selected in relation to their primary type of medium (primarily print or online), and the role they play in that particular media form. Finally, we interviewed individuals working in the 'arts and culture' sector relating to video games, such as directors of video game museums. Additionally, gender and age were also taken into consideration, to try and again get a diverse range of participants; which provided us with sample age range of 24-54 and a gender divide of 7 women and 21 men (among video gamers the divide was fifty-fifty). Interviews were recorded, transcribed, and analysed thematically. Also notes were taken from more informal conversations and communications with the interviewees and fed into the research; such as information about their work and experiences.

\section{Video Games and the Contemporary Nature of Agency}

Primarily based on actor-network theory and Foucauldian theory, we will expound our approach to agency. Following an actor-network approach, there are three fundamental characteristics that define agency (Muriel, 2016). These are: first, that agency produces differences and transformations; second, that the characteristics of agency are multiple 
and do not reside in any one prototypical actor; and third, that agency is distributed and dislocated.

First of all, then, agency is what produces differences and transformations. Agency exists because, in some way, it transforms reality. Agency, therefore, does not have to do with the intention, desire, or the will of an actor, but rather with the transformations that occur; which are effectively observable and traceable:

Without accounts, without trials, without differences, without transformation in some state of affairs, there is no meaningful argument to be made about a given agency, no detectable frame of reference (Latour, 2007: 53).

Thus, the core of all agency is that it produces some type of change or it does not exist. The agency of a specific actor can then only be defined 'through its action' (Latour, 1999a: 122). That is why video games - but also the hardware, connections, and peripherals that make the interaction possible - can be considered as actors. In that, their actions bring about change: 'The player does not act so much as he reacts to what the game presents to him $[s i c]$, and similarly, the game reacts to his input' (Arsenault and Perron, 2009: 119-120). The language of our interviewees reflects the agency of video games by recognizing how they have an impact on reality, particularly on the people who play them. We see how video games 'can bring people together' (Andrew, male, 28, dedicated and self-identifying gamer), 'provide a sense of friendship', (Zelda, female, 25, highly involved in the culture but only mildly identified as gamer), 'have an effect' (Steffan, male, 45, manager at a video game university) on gamers, or even 'overwhelm you or make you think twice' (Laura, female, 26, indie game developer and artist).

The second characteristic of agency is that it is multiple and does not reside in a prototypical actor. That is to say, action can be 'embodied' in very different formulas 
and does not necessarily entail any standard actor (Latour, 2007: 54). And in exploring the forms of actors and actions, we begin to see the multiplicity of agency (Latour, 2007: 55). Thus, we emphasize 'the open character of agency, which can be occupied by the most heterogeneous mix of humans and non-humans' (García Selgas, 2007: 144). This results in tremendous freedom to define what an actor is: from understanding it as an extremely complex and abstract entity (institutions, the rail network, the human body, for instance), to thinking of it as a concrete person or object (such as, the president of a government, God, the authors of this text, a particular video game). In short, it is a question of recognizing the heteromorphism of agency. In this sense, as Millington (2009: 622) contends, video games are paradigmatic for human and nonhuman transgression and hybridity, which blurs the distinctions between people and machines and demands 'reconsideration of the ontological status afforded to humans, and have created a need for renewed epistemological approaches'.

This can clearly be seen in those video games that explicitly seek to disempower the player. For example, This War of Mine (11 bit studios, 2014), where the player plays the roles of civilians in a city sieged by war. The lack of tutorial leaves players on their own; the game disorientates them, and they do not necessarily immediately know how things work. Or the Dark Souls (FromSoftware, 2011-2016) series, which punishes the mistakes that players make enormously, forcing them to repeat several times the same action, facing the same enemies, and passing through the same scenarios. Also, certain horror video games such as Outlast (Red Barrel Studios, 2013), Amnesia (Frictional Games, 2010), or Alien Isolation (Creative Assembly, 2014) consist of putting the player in the shoes of an extremely vulnerable individual, who is only able to flee or hide from their enemies, with almost no means to defend themselves in a direct way. These are examples in which it is possible to see how video games are also viable 
actors, because they interfere in the course of action of players. In this sense, we also found that an important number of interviewees described how video gaming could result in experiences of failure and loss of agency.

Suddenly, something went wrong in the game. Then, you have to adapt, you can't control everything. So you have to make some decisions and adapt to those changes (Laura).

In this sense, Helen Thornham (2011: 82), who carried out an ethnographic study on video gamers in various households in the UK, similarly asserted that if video games have the power to cause interruptions and disruption to players' conversations and gameplay, they should then 'be afforded affective agency'. There are so many agents (human and not) that can condition and disrupt what the player is doing that it is difficult to disregard their influence.

Agency is also multiple in that it is configured relationally. For someone or something to be situated as a personification and act as a social agent, there must be an interaction among agents (García Selgas, 2007: 140). Thus, the fact that agencies appear in subject-positions or as concrete personifications - assembled, institutionalized, stabilised - is an effect. Video games, video gaming platforms and networks, video gamers, developers, video game websites and broadcast channels, and artistic and social representations of video game culture are, in the end, the outcome of complex associations between different human and non-human actors. This is perfectly shown in the idea of video games as assemblages (another notion that is very important in actornetwork theory; particularly in Latour's works):

Games, and their play, are constituted by the interrelations between (to name just a few) technological systems and software (including the imagined player embedded in them), the material world (including our bodies at the keyboard), the online space of the game (if any), game genre, and its histories, the social worlds that infuse the game and situate us outside of it, the emergent practices of communities, our interior lives, personal histories, and aesthetic experience, institutional 
structures that shape the game and our activity as players, legal structures, and indeed the broader culture around us with its conceptual frames and tropes (Taylor, 2009: 332)

The final characteristic of agency, describes it as distributed and dislocated. This notion of agency ignores 'the alternative between actor and system' (Latour, 2007: 216), dealing with the action-structure dualism that has limited the social sciences since its beginnings. Understanding that action is not born within an individual's consciousness, the fact that the individual can almost never do what they want to do is not explained by attributing this to an external social force, such as the habitus, society, the group or any other specific aspect of reality that appropriates conduct (Latour, 2007: 43-46). The explanation lies in the idea that action is dislocated (Latour, 2007: 46), and not reducible to any predefined social categories such as those mentioned. Action, therefore, is not the direct product of the actor, but nor is it the product of the structure in which, in conventional terms, it is inserted. The social is, then, not made 'of agency and structure at all, but [is] rather a circulating entity' (Latour, 1999b: 17).

Moreover, we would suggest that the distributed nature of agency is clearly visible in video games and, as Giddings (2009: 148) argues, 'we should resist conceiving of the video game as a discrete and "whole" object'. A gaming experience is therefore an event in which human subjects, a set of technologies, and a mediacultural practice come together; an event that 'emphasizes the dynamic between the elements in play: entities coming together, material and aesthetic chains of cause and effect or feedback' (Giddings, 2009: 149), which can only 'be adequately addressed through acknowledgement of its bringing together of heterogeneous part(icipant)s' (Giddings, 2009: 150).

All in all, agency can be summarized as what produces changes and transformations in reality. Hence, having this definition of agency, how do we then 
define what should be considered as change and transformation in a particular social context? We find an interesting answer in Foucault's theory.

Apparatuses, or dispositifs, limit what happens inside of them, and are the principal manifestations and enactors of the conditions of possibility for a specific society and time. Foucault used the notion of dispositif (or apparatus in the most common translation of the term in English) in his works Discipline and Punish (1995) and the first volume of The History of Sexuality (1990). In a conversation with other intellectuals, he defined the concept as follows:

What I'm trying to pick out with this term is, firstly, a thoroughly heterogeneous ensemble consisting of discourses, institutions, architectural forms, regulatory decisions, laws, administrative measures, scientific statements, philosophical, moral and philanthropic propositions - in short, the said as much as the unsaid. Such are the elements of the apparatus. The apparatus itself is the system of relations that can be established between these elements (Gordon, 1980: 194).

We face again the conjunction of heterogeneous elements, an assemblage of actors, and, above all, the way in which they intertwine. Rather than defining a structure formed by a group of diverse pieces that fit together in a particular mode, it is about identifying the nature of the connection between those elements. It also should be pointed out that the dispositif produces and is produced by certain power-knowledge relations, which entail 'a certain manipulation of relations of forces, either developing them in a particular direction, blocking them, stabilising them, utilising them, etc.' (Gordon, 1980: 196). In this process there is always a strategic function, that is, the dispositif is born to respond to 'an urgent need' (Gordon, 1980: 195). However, these are strategies that 'no one is there to have invented them, and few who can be said to have formulated them' (Foucault, 1990: 95), what creates confusion: the dispositif appears as a rational, coherent, and global strategy, but is formed by multiple contradictory and dissimilar 
operations that oppose each other; it is intentional and, at the same time, non-subjective (Foucault, 1990: 95). As Latour notes, purpose is neither a property of humans nor of objects, but, precisely, it is an attribute of dispositifs, apparatuses, institutions, or, as we would like to suggest, assemblages:

Purposeful action and intentionality may not be properties of objects, but they are not properties of humans either. They are the properties of institutions, of apparatuses, of what Foucault called dispositifs. Only corporate bodies are able to absorb the proliferation of mediators, to regulate their expression, to redistribute skills, to force boxes to blacken and close. [...] Boeings 747 do not fly, airlines fly (1999: 192-193).

In video games, players' agency is delimited by the system - what they can see, say and do - as in any other social interaction mediated by the dispositifs in which we live. Another question is to think that the system, dispositif, apparatus, or assemblage have well defined contours: players are limited or enabled by the video game but also by the technology, the developers, other players, and many more social actors (human and not); some of them are close in time and space, others are acting at a distance (Latour, 1987: 219-232). This can be seen in how other agents - not necessarily human - are able to condition the player's agency, who, in some instances, feels that they are losing their ability to control the situation. This could be another person, the video game, or even the Internet connection:

I like to play by myself and think by myself to see how I'm going to beat my opponent. But as soon as he looks around the shoulder, you think "Go away!", because he starts influencing the whole thing, which becomes quite annoying (Zelda)

But what I really annoy is actually the Internet that goes off. That annoys me most. [...] The Internet went out and I couldn't do anything. Then when it finally reappeared I apparently lost [laughter]. [...] I don't like it when I lose because of something beyond my control. (Zelda)

Hence, we face a paradox that other theorists have previously found. For instance, Giddings (2009: 151) suggests that 'video game players are acted on as much as they 
act', and highlights the game event 'as one constituted by the playful translation of agency, the eccentric circuits of effect and affect, between human and nonhuman components'. There are also those who have approached this paradox by conceptualizing it in terms of balance (such as Krzywinska, 2007) or even as an illusion: 'The illusion of interactivity sponsors a sense of agency - but this agency has been externally predetermined or pre-designed' (Charles, 2009: 286). It therefore appears, that video games offer a 'directed freedom' (Navarro-Remesal and GarcíaCatalán, 2015). This apparent contradiction is perfectly summarised by Tulloch:

The player is at the same time active agent and prisoner of the system, author of events, and slave to the game's authority, creative contributor and mindless automaton. Paradoxically, play is understood as being contingent upon both agency and compliance (Tulloch, 2014: 336).

Nevertheless, Tulloch goes beyond this theoretical conundrum and offers a solution that tries to work around this trap. Drawing on Foucault's notion of power and agency, where both are (re)produced through each other instead of being in opposition, Tulloch proposes that players' practices and expectations are 'shaped by the game, but at the same moment, the game only comes into being by their play' (2014: 348). Both are needed - along with other elements - in order to exist; they are part of the same productive force. The Foucauldian dispositif explains this duality, as Poltronieri (2015: 174) has noted: 'The player is free to take action to reach desired results as long as these actions are codified in the interior of the apparatus'. The dispositif limits and allows all that can be seen, said, and done, within a regime of truth, but, as it is necessarily reproduced through the generative force of agency, it contains the potentiality to break itself and produce new ones. Agency is thus constructed in that circulation of heterogeneous entities that are mutually influencing each other. 


\section{Agency and Neoliberal Political Rationalities: Control, Freedom, and Responsibility}

We have seen so far what video games tell us about agency as what produces transformations in a multiple, distributed, and dislocated way. Video games help us to visualize the nature of agency in contemporary society as a post-human, assembled, and relational process. Moreover, they do this within dispositifs, apparatuses, and assemblages that regulate and give meaning to those transformations. However, a fundamental question is still pending: What are the political rationalities that define the contemporary dispositifs?

According to Miller and Rose (2008: 58), political rationalities can be understood as the regularities in the political discourse for 'the formulation and justification of idealized schemata for representing reality, analyzing it and rectifying it'. There are three main characteristics that define political rationalities (Miller and Rose, 2008: 58-59). First, political rationalities possess a moral form; they are based in principle that guide the tasks of government such as freedom, justice, equality, mutual responsibility, citizenship, common sense, economic efficiency, prosperity, growth, fairness, or rationality. Second, political rationalities have an epistemological character; they are articulated in relation to an idea of the nature of the objects governed such as society, the nation, the population, or the economy. Third, political rationalities are expressed in a particular idiom; it is a language that works as an intellectual machinery for making reality thinkable under certain political deliberations. In sum, political rationalities are 'morally coloured, grounded upon knowledge, and made thinkable though language' (Miller and Rose, 2008: 59). In contemporary society, the hegemonic political rationalities are those associated with neo- or advanced-liberalism.

In neoliberalism, the relationships between the public and private spheres are resignified as part of a progressive weakening of the State, what Gordon (1991: 36) 
calls 'modes of pluralization of modern government'. This draws a society of subjects responsible for their own government. The powers of the State are then aimed at empowering entrepreneurial individuals capable of choosing for themselves. This new post-Keynesian and post-Fordism reality requires a self-regulated subject, which can be defined as 'active, responsible, participative, and dynamic' (De Marinis, 2005: 25). It is the fundamental logic of neoliberalism in which citizens are governed through their 'freedom to choose' (Miller and Rose, 2008: 82). Thus, freedom and control, individual autonomy and government, are not opposing pairs; they are an inseparable part of a new formula of handling and defining realities. The discursive figures of freedom, control, and responsibility are, therefore, essential to understand agency in contemporary society, which can be extended to the social universe that emerges around video games.

Thus, most representations of player's agency in video games revolve around the idea that they are the protagonist; the one in charge of manipulating the flow of what is happening on the screen. This leads to the common assumption in gaming cultures, evident with our interviewees, that video games represent a (more) interactive cultural form:

So reading is great, but reading, you're always an observer to it. Whereas in video games, it's the same story, however, you are not an observer anymore, you're actually in that story (Alfred, male, 26, strong identification as gamer).

According to this discourse, players do not merely observe, they are in the story, they belong to and are an operational part of the narrative and mechanic processes of video games. Video games force players to engage with them: 'to think that you are the one who is playing, what happens to the character is happening to you' (Patxi, male, 38, game developer and programmer). This is a generalised feeling among the vast majority of the interviewees, which leads them to claim that 'you almost feel you are the one 
who is inside the screen' (Iker, male, 43, an infrequent gamer). Definitely, video games foster this view in both explicit ways (as in the series of titles we alluded to in the introduction, which are continuously reminding the player that their choices will have an impact on the story) and implicit ways (using different camera points of view, filling the screen with dozens of missions and elements to be discovered, or allowing various forms of character and game universe customization). The player is then 'pushed' to become the central agent in the system.

In this sense, the rhetoric of freedom is also the cornerstone of video games. Players often feel that video games enable them to act and go where they choose inside the universe of the game. As expressed by some of our research participants, such as, 'Isidoro' (male, aged 27, a director of a documentary on video games) and 'Iker':

Shadow of the Colossus. It's a huge world but you only need to go from point A to point B. However, you have the freedom to ride with your horse. [...] And you say to yourself: 'I am free to explore this land' (Isidoro).

Grand Theft Auto. It may be an adventure game but it offers you a lot of freedom. I play some of its missions but in the end I realise that, instead of doing what I'm supposed to do, I just grab a car and start wandering around (Iker).

This is the idea behind, what it is known in the field of video games, as 'open worlds', which are not only linked to MMOs such World of Warcraft (Blizzard Entertainment, 2004) or Eve Online (CCP Games, 2003), but also includes works - related to the sandbox genre of games - with vast maps to explore and a non-linear gameplay, enabling and fostering emergent narratives. These games are based on the idea of giving freedom to players in order to explore the universe of the game and act without following a pre-established script, allowing players to choose what missions they want to accomplish and in which order, and flooding the story with secondary tasks and minigames. The Elder Scrolls (Bethesda, 1994-to date), The Witcher (CD Projekt RED, 
2007-to date), Grand Theft Auto (Rockstar Games, 1997-to date), Assassin's Creed (Ubisoft, 2007-to date), Fallout (Bethesda, Obsidian, 1997-to date), and Mass Effect (BioWare, 2007-to date) series are some of the paradigmatic examples of this approach that articulates the gameplay experience around the idea of free will, which is nothing else than the maximization of the principle that rhetorically governs every video game: player freedom.

Every time players decide to ignore the main story and freely walk in Liberty City or Tamriel (the realms of, respectively, Grand Theft Auto and The Elders Scrolls series), choose the next dialogue line that will define their relationship with other characters, or follow all those markers that inundate maps with the tasks to do, they are reproducing ideas of freedom that can be found in the neoliberal rationale, where individuals are not 'merely free to choose, but obliged to be free, to understand and enact their lives in terms of choice' (Rose, 1999: 87). Following in Foucault's footsteps, Nikolas Rose (1999) reframes 'freedom', not as the opposite of power, but as its condition of possibility. There is no power without freedom - the possibility to choose in the same way there is no freedom that has not been born in the tension of complex power relations. In Foucault's (2003: 139) words, there is needed a 'field of possibilities in which several kinds of conduct, several ways of reacting and modes of behaviour are available'. Video games are therefore not detached from the dominant political rationalities; games are shaped by the existing social forces, as much as they contribute to mould them. The requirement to interact, choose, and decide is fundamental, including a demand to have an influence:

Looking at computer games, you can clearly see for example our demand for $[\ldots]$ the idea that we have an influence, that we have the option to interact (Andreas, male, 51, head of a video game museum). 
It's a video game because I can make decisions about what is happening. I mean, I can affect this world or this thing I'm interacting with (Javier, male, 32, game developer and programmer)

This conceptualization of video game players puts them in the centre of the discussion on agency, which enables the recognition of players as the most important social actors here (something that, as we saw above, this text questions). It is not surprising then that a dominant discourse exists that focuses on how players are in control of the situation. Video games can only be defined as such if you, as the player, 'are in charge' and, in addition to that, 'control what is happening' (Isidoro). In the end, 'video games are about making decisions' (Patxi) and 'choosing your own path' (Minerva, female, 37, game developer and artist). In this sense, video games, are clearly looking for active individuals; they are promoting the production of participative agents because otherwise the articulation of these two elements (video game players and video games) would not be possible:

It's what makes it an active thing as opposed to a passive thing. You actually have to go off and do something to make something happen, or if nothing will, nothing will happen (Albert, a male 25 year old, game developer and artist).

This is paradigmatic of how an active subject is fundamental to understand agency when it comes to video gaming. For example, this is the point of view that EgenfeldtNielsen et al. (2008: 138-139) offer when they consider that video games demand players to explicitly interact with them; requiring 'the user to engage in play'. Moreover, the involvement of the player with the video game seems to be essential: 'it's really you who win and lose' (Kirby, 2009: 169). In this context, video games are about 'power fantasies' (Peter, 54, male and lead of a video game-related master's degree programme) and being in control:

The reason why games like Candy Crush are very popular is because they give you a sense of control of daily life that you don't normally have $[\ldots]$ Things are like they should be in your real life. Hard work is 
rewarded, you have control of it (Darius, male, 28, game designer and developer)

This, then, casts players as powerful subjects, who are able to control the outcome of their actions in ways they could only imagine in their daily lives. As Oliva, PérezLatorre, and Besalú (2016: 12) argue, paratexts around video game culture (in their case video game covers) urge the player "to "choose", "collect", "manage" and "win", defining what we should expect of a good game or a good player experience', which directly links this experience to neoliberal rationalities. Video games create then an environment (rhetorical but also material) where players' agency is inflated and promotes a sense of achievement and empowerment. In a more or less explicit way, video games facilitate the notion that players, if they are accomplished enough or try hard enough, are able to succeed and triumph:

You always have to be kind to players. You want to make them feel that they are winning (Craig, male, 41, game developer and programmer)

There's sometimes quite subtle and sometimes really explicit message to do with empowerment. You can do it. You can do this (Emmett, male, 47, and head of a video game-related exhibition).

Video games produce the opportunities for these narratives of success, where the player is the winner and the one who can do whatever she or he resolves to do. It is the projection of an empowered and determined individual who can overcome any obstacle in their way. This representation of agency falls into the classic identification of human beings as conscious, active, and intentional subjects, which celebrates 'the emancipation of the rational or working subject' (Lyotard, 1984: xxiii) of modernity.

At an ontological level, this approach to agency ignores the idea of agency as multiple, distributed, and dislocated that we saw above. It maintains the dualism that divides those types of entities considered to be active (the human, the subject, the social) and those that are seen to be passive (the non-human, the object, nature) — as if 
agency was not, in fact, everywhere (Law, 2004: 131-134). At a more sociopolitical level, this perspective reflects and reinforces the political rationalities of neoliberalism, in which one of its central axioms is the construction of an active, autonomous subject who takes care of themselves and, at most, participates with others in order to solve their specific problems (Rose, 1999: 137-166).

Furthermore, this approach ignores the loss of agency that many players experience while playing video games. There are even interviewees who directly link feelings of failure to the very act of video gaming: 'Frustration is the main emotion that I associate with video games' (Elisabeth, female 25, an infrequent gamer). When the player's agency is interrupted or does not offer the expected outcome, thence, the frustration appears:

But if you play something that's very clunky or unresponsive, it makes it very frustrating, because you press this button and it's not doing what you want it to do. That could bring a lot of frustration. (Andrew, male, 28, frequent, dedicated, and self-identifying gamer).

Titan Souls is definitely a punishing game. If you make a single mistake, you'll die, and you have to run back. That is very punishing (Noel, male, 24, indie game designer and developer).

Thus, video games can be seen as devices that, at the same time, enable and condition the player's agency. According to Brookey and Booth (2006: 218), in most video games, 'the player is not given the agency to change the game's structure and design', and therefore limitations are imposed on the choices available to players, which 'do not always allow for the kinds of changes that could be equated with ideological resistance'. This approach is similar to Manovich (2001: 34) take on interactivity in video games, which, he suggests, is conditioned by the coded nature that rules video games: 'computer characters can display intelligence and skills only because the programs put severe limits on our possible interactions with them'. However, video game culture is generally traversed with this idea that players are responsible for controlling the game, 
and, moreover, are willing to do so:

Typically I wouldn't read a guide or a walkthrough, because I'd like to be able to do it myself (Alfred).

When you play by yourself, you mainly want to get through the story, get through the game, and try and work it out. But you want to work it out by yourself rather than relying on other people (Zelda).

If, according to the apparatuses in which they dwell, the condition of possibility of video gamers' agency is their freedom to choose, then both their achievements and failures are their responsibility. Hence, although there are numerous of our interviewees who acknowledge that there are several moments in which they are at mercy of the video games they play or other external factors, there is still a tendency to reintroduce the importance of the player as the agent who is capable of overcoming these obstacles, even though they may continue to fail:

They are very vulnerable, you know, one hit get them killed. It is kind of like they have no real power, because they're so fragile. When you as a player become more skilled in it, you understand that you have all the power, because you control these titans and you can kill them (Noel).

For this developer, who is speaking of his video game (renowned for its high difficulty), the loss of agency, the fragility, and the sense of powerlessness are seen as temporary: the player has the ability to succeed, and if they fail, it is because of their lack of skill or because they did not invest enough time perfecting their skills. As Juul (2013: 7) has asserted in his essay on video gaming failure, video games 'promise us a fair chance of redeeming ourselves', which 'distinguishes game failure from failure in our regular lives'. However, even if video games are more explicit about the redemption opportunities they offer, we see there are similarities between failures in video games and in our regular lives. In a neoliberal society, individuals, or at most particular groups or communities, are to be held responsible for their own situation without considering any structural conditioning that might be affecting them. The rhetoric here, in video 
games, as it is in wider society, is that should they exert themselves, they will be able to achieve their goals, or else they will fail due to their own deficiencies or lack of effort.

In this sense, Bulut, Mejia, and McCarthy (2014) explore the intersection between the ludic sublime, understood as a form of techno-utopianism in which video games are presented as a solution to political problems, and neoliberalism as a way to approach social action and citizenship in a postmodern world. According to Bulut et al. (2014: 347), in societies that are marked by neoliberal political rationalities, "personal responsibility operates as the master trope of society' and the ludic sublime reimagines citizens as players in the game of life. This has as a consequence that 'those who play the game well are rewarded and those who play poorly are punished'. This points then to a 'ludic reconfiguration of political rationality' that affects people's agency. What we see about agency in video gaming reflects how agency works in wider society.

Video games therefore require the player to take control of what they have in front of them - in a literal sense most of the times, since the player has to use a physical game controller - and are usually made accountable of both their achievements and failures. No matter if, as we have shown, video games, developers, or other agents, may severely condition video gamers' agency, it is widely established within video game culture that outcomes are primarily determined by the player. This is similar to what Shaw (2014: 13-39) found in the options video games offer in terms of representation. In principle, video games seem to propose different alternatives of representation; gamers are given the freedom to choose between various characteristics, including race, gender, physical appearance, and at times, even sexuality. However, in the end, the video game is placing the burden of representation on the video gamers: 'rather than include diversity in games with set characters, most representation of marginalized groups and identifiers is placed in the hands of players' (Shaw, 2014: 35). 
Neoliberalism, after all, seeks to 'govern using the maximum amount of energy available from the people who are to be governed' (De Marinis, 2005: 22). This is something we repeatedly see in video games; the individual is understood as the entrepreneur of himself or herself' (Gordon, 1991: 44). The promotion of active, selfresponsible, and participative individuals, then, cannot solely be reduced to a disposition in some subcultural forms, but rather it is connected to wider tendencies that affect society as a whole.

\section{Conclusions: Limits and Promises of Agency in a Changing Society}

In this text, we have explored agency in video game culture. The obsession of the medium with offering an experience of free will, difficult choices, actions with consequences, and a generalised discourse about the centrality of the video game player, leads us to argue that studying video games and their culture constitutes an optimal field in which to approach questions related to the contemporary nature of agency, interactivity, freedom, and power.

In particular, the rich variety of actors in video game culture leads us to question traditional ideas of agency, as we are dealing nowadays with more complex networks of actors, interactions, and power than before. Video games contribute to subverting the received theoretical status of agency, and indicate how it has changed over the last decades and how we need new approaches to it. Video game culture is proof of an ontologically promiscuous notion of agency that requires new epistemological lenses; new lenses that help us blur the generic face of humanity as a modernist figure and reconfigure it in the frame of a post-humanist landscape (Haraway, 2004: 47).

Similarly, video games show us that, today, agency is, at the same time, part of both emancipatory and alienating practices. Not only is agency linked to freedom, 
empowerment, and autonomy, but it is also connected to submission, disempowerment, and dependency. Limitations and potentialities are both part of the same uses of agency. Video games and the agency they promote might be part of the current neoliberal rationalities, but they carry the promise of new creative and critical modes of agency.

In this sense, freedom is enclosed in a context that promotes it in a fashion that does not let agency break the hegemonic discourses, practices, and systems. However, because these neoliberal rationalities foster the ideal of the autonomous self-governed subject, they are letting this agency produce lines of breakage. In this regard, neoliberalism has been very successful in two aspects: giving choices to individuals, and making them responsible for the decisions they make. It can be said that the forces of neoliberalism have been so successful that they have planted the seed of its potential demise. Its rationalities have promoted so feverishly individual freedom and selfresponsibility that they have created a largely autonomous subject, one that, to a certain extent, may be able to escape its rationalities. After all, Deleuze considered that every dispositif had two set of groups: 'lines of stratification or sedimentation and lines leading to the present day or creativity' (1990: 165). The latter includes among them the lines of 'splitting, breakage, fracture' (1990: 162); those that outline the movement from one dispositif to another (1990: 161).

This points to the possibility to break the system, like when people look for glitches in video games, ways to outsmart them. Or when communitarian forms of agency are articulated, sharing the responsibility of the process of creation, which transforms the works and culture beyond their original design (wikis, cosplay, derivative works, mods, new games, fan fiction and art, walkthroughs, and so on); in other words, there is also social and political space for a 'participatory culture' (Jenkins, 2006; Jenkins et al., 2005). Video games assemblages contain powerful agencies that 
could transform, and are currently transforming somehow, reality.

Therefore, we have here a notion of agency linked to neoliberalism, but this could drift equally towards the reproduction of its rationalities, reinforcing the liberal thinking and practices, or towards its rupture, exploring new modes to articulate power relations and imaging an agency that helps transform reality in other ways; such as a more communitarian form of conducting ourselves, sharing responsibilities, acknowledging those who are systematically in a position of subalternity, and promoting diversity.

\section{References}

Arsenault, Dominic and Perron, Bernard (2009). "In the Frame of the Magic Circle: The Circle(s) of Gameplay", in Wolf, Mark J. and Perron, Bernard (editors). The Video Game Theory Reader 2. New York: Routledge,109-131.

Brookey, Robert Alan and Booth, Paul (2006). "Restricted Play. Synergy and the Limits of Interactivity in the Lord of the Rings: The Return of the King Video Game", Games and Culture, 1(3): 214-230.

Bulut, Ergin; Mejia, Robert; McCarthy, Cameron (2014). "Governance through Philitainment: Playing the Benevolent Subject", Communication and Critical/Cultural Studies, 11(4): 342-361.

Calleja, Gordon (2011). In-Game: From Immersion to Incorporation. Cambridge, MA: MIT.

Charles, Alec (2009). "Playing with one's self: notions of subjectivity and agency in digital games", Eludamos, 3(2): 291-284.

Crawford, Garry (2012). Video Gamers. London: Routledge.

De Marinis, Pablo (2005). "16 comentarios sobre la(s) sociología(s) y la(s) comunidad(es)", Papeles del CEIC, 15:1-39.

Debord, Guy (1995). The Society of the Spectacle. New York: Zone Books.

Deleuze, Gilles (1990). "What is a dispositif?" In Armstrong, Timothy J. (editor). Michel Foucault Philosopher. New York: Routledge, 159-168.

Egenfeldt-Nielsen, Simon; Smith, Jonas Heide; Pajares Tosca, Susana (2008). Understanding Video Games: The Essential Introduction. New York: Routledge.

Foucault, Michel (1990). The History of Sexuality, Vol. 1: An Introduction. New York: Vintage Books.

Foucault, Michel (1995). Discipline and Punish: The Birth of the Prison. New York: Vintage Books. 
Foucault, Michel (2003). "The Subject and Power" in Rabinow, Paul and Rose, Nikolas. The Essential Foucault. New York: The New Press, 126-144.

García Selgas, Fernando J. (2007). Sobre la fluidez social. Elementos para una cartografía. Madrid: CIS.

Giddings, Seth (2009). "Events and Collusions. A Glossary for the Microethnography of Video Game Play", Games and Culture, 4(2): 144-157

Gordon, Colin (1980). Power/Knowledge. Selected Interviews \& Other Writings. 19721977. Michel Foucault. New York: Pantheon Books.

Gordon, Colin (1991). "Governmental Rationality: An Introduction" in Burchell, Graham; Gordon, Colin; Miller, Peter. The Foucault Effect. Studies in Governmentality. Chicago: Chicago University Press, 1-51.

Haraway, Donna (2004). The Haraway Reader. New York: Routledge.

Jameson, Frederic (1991). Postmodernism. Durham, NC: Duke University Press.

Jenkins, Henry (2006). Fans, Bloggers, and Gamers. Exploring Participatory Culture. New York: New York University Press.

Jenkins, Henry; Purushotma, Ravi; Clinton, Katherine; Weigel, Margaret; Robison, Alice J. (2005). Confronting the Challenges of Participatory Culture: Media Education for the $21^{\text {st }}$ Century. Chicago: MacArthur Foundation.

Juul, Jesper (2010). A Casual Revolution: Reinventing Video Games and Their Players. Cambridge, MA: MIT Press.

Juul, Jesper (2013). The Art of Failure. Cambridge, MA: MIT.

Kirby, Alan (2009). Digimodernism. New York: Continuum.

Krzywinska, Tanya (2007). "Being a determined agent in (the) World of Warcraft: text/play/identity". In Atkins, Barry and Krzywinska, Tanya (editors). Videogame, Player, Text. Manchester: Manchester University Press, 101-119.

Latour, Bruno (1987). Science in Action. Cambridge, MA: Harvard University Press.

Latour, Bruno (1999a). Pandora's Hope. Essays on the Reality of Science Studies. Cambridge,MA: Harvard University Press.

Latour, Bruno (1999b). "On recalling ANT”. In Law, John and Hassard, John. ActorNetwork Theory and After. Oxford: Blackwell, 15-25.

Latour, Bruno (2007). Reassembling the Social. An Introduction to Actor-NetworkTheory. Oxford: Oxford University Press.

Latour, Bruno (2017). Facing Gaia: eight lectures on the new climatic regime. Cambridge: Polity Press.

Law, John (2004). After Method. Mess in social science research. London: Routledge.

Lyotard, Jean-François (1984). The Postmodern Condition. Minneapolis: The University of Minnesota Press.

Manovich, Lev (2001). The Language of New Media. Cambridge, MA: The MIT Press

Miller, Peter y Rose, Nikolas (2008). Governing the Present. Administering Economic, Social and Personal Life. Cambridge: Polity Press.

Millington, Brad (2009). "Wii has never been modern: 'active' video games and the 
'conduct of conduct'”, New Media Society, 11(4): 621-640.

Muriel, Daniel (2016). "Toward a Sociology of Mediations: Impressionist Mapping and Some (Brief) Rules for a Sociological Method", REIS, 153:111-126.

Navarro-Remesal, Víctor and García-Catalán, Shaila (2015). "Let's play master and servant: BDSM and directed freedom in game design". In Wysocki, M. and Lauteria, E. W. (Eds.). Rated M for Mature. London: Bloomsbury, 119-132.

Oliva, Mercè; Pérez-Latorre, Óliver; Reinald Besalú (2016). "“Choose, collect, manage, win!': Neoliberalism, enterprising culture and risk society in video game covers", Convergence, DOI: 10.1177/1354856516680324.

Poltronieri, Fabrizio (2015). "Communicology, Apparatus, and Post-history: Vilém Flusser's Concepts Applied to Video games and Gamification". In Fuchs, Mathias; Fizek, Sonia; Ruffino, Paolo; Schrape, Niklas. Rethinking Gamification. Lüneburg: Meson Press.

Rose, Nikolas (1999). Powers of Freedom. Reframing Political Thought. Cambridge: Cambridge University Press.

Salen, Katie and Zimmerman, Eric (2004). Rules of Play: Game Design Fundamentals. Cambridge, MA: MIT Press.

Shaw, Adrienne (2014). Gaming at the Edge. Minneapolis: University of Minnesota Press.

Taylor, T. L. (2009). “The Assemblage of Play”, Games and Culture, 4(4): 331-339.

Thornham, Helen (2011). Ethnographies of the Videogame. Gender, Narrative and Praxis. Surrey: Ashgate.

Tulloch, Rowan (2014). "The Construction of Play: Rules, Restrictions, and the Repressive Hypothesis", Games and Culture, 9(5): 335-350. 